Knowing the implicit confidence in the effectiveness of this kind of concealment, which is instructive in all creatures furnished with the necessary apparatus, I proceeded to try and test this very curious psychological accompaniment of the physical machinery. I advanced in the full sunlight close up to the moth - -so close that I could see the prominent "beaded eyes" with the watchful look-and the ronghened outlines of the thorax, which served to complete the illusion. So perfect was the deception that I really could not feel confident that the black spot I was examining was what I believed it to be. Only one little circumstance reassured me. There was some hole or interstice in the outer covering, through which one spot of the inner brilliant margin could be seen shining like a star. Certain now as to the identity of the moth, I advanced still nearer, and finally I found that it was not till the point of a stick was used to move and shake the earth on which it lay, that the creature could believe that it was in danger. Then, in an instant the crumpled leaf became a living moth with powers of flight, which would have defied capture.

$\mathrm{I}$ recollect that many years ago $\mathrm{Mr}$. Wallace kindly showed me a butterfly from the Eaitern Archipelago whose upper wings were of a brilliant colour, but which, by the simple act of alighting on a branch, and of folding or closing its wings, became transformed into the perfect likeness of a growing leaf-a likeness so perfect that even the closest inspection only discovered new items of resemblance-inasmuch as the leaf-stalk, as well as the venation of the leaf, were all perfectly represented both in the structure and in the colouring of the under-surface of the wings.

I confess that the number and intricacy of the correlated growth and instincts which are involved in the:e phenomena strike me more and more as wholly outside the sphere of mere physical causation-by which I do not mean that physical causation has not had its own share of instrumentality in the matter, but that it affords no satisfying explanation of all the elements involved. The ordinary phrases of the Natural Selection Theory appear in the light of such facts to be little better than lean and empty formulæ.

Cannes, November 29 ARGYLL

\section{Double Flowers}

I AM indebted to Baron von Mueller for the communication of double flowers of Tetratheca ciliata, which possess interest on several grounds, although the changed appearances they present are not infrequent. It may be well to premise (I) that the plant, like all its $f$ llows of the same order (Tremandraceæ), is native to extra-tropical Australia ; (2) that, under ordinary circumstances, it has 4 free sepals, 4 free petal, 8 free stamens in a single row, and a two-celled ovary; (3) that "doubling," in a strict sense, is brought about by the multiplication of petals, or by the more or less complete substitution of petals for stamens, or pistils, or both.

The Australian origin of the plant in question is so far of interest, in this connection, that it affords one more illustration of the occurrence, under natural conditions, of double flowers in a division of the globe where, according to the late Dr. Seemann, such forms are rare. The rarity, however, I believe, is not so much in the existence of such flowers, as in the number of observers, at any rate we now know of several cases of the kind.

Some of the flowers sent by Baron von Mueller were double by multiplication of petals, i.e. there was a second row of petals inside the first, others were double not only by multiplication of petals, but also by the partial substitution of petals for stamens ; thus in one of these last-mentioned flowers, there were four sepals, three rows of petals, one of the innermost row being partly staminoid, and eight stamens in a single row. Of these eight stamens, six were perfect and the remaining two partially petaloid, one lobe of the ordinarily 4-celled anther being destitute of pollen, but enlarged into a relatively large petal-like lobe with inflected margins. So that according to the old notion, this flower affords an instance both of progressive and of retrogressive metamorphosis, of enbanced and of arrested development associated with compensatory changes. On the hypothesis revived by Mr. Grant Allen-for it is no new notion - the two outer rows of petals would be stamens flattened out of all knowledge, while the inner row and the staminal whorl would, I presume, also afford him evidence of the truth of his opinion. For my own part I prefer to adhere to the established order of things, in which the horse precedes, rather than follows the cart, and I do so because to do otherwise would be to run counter to what we know of the homologies of the foliar and floral organs, of leaf-buds and flower-buds, and to ignore or rather to reverse what we know of the mode and order of development of flowers in general.

Not being aware of the precise order of evolution in the flower in question, I can only reason from analogy when I express my opinion that the changes it presents and the order of arrangements of its parts from the leaves on the flower-stems up to the pistil are more consistent with the generally adopted views of morphology than they are with Mr. Grant Allen's. According to his views, so far as I understand them, I can see no reason why the sepals as well as the petals should not be flattened stamens, and if the sepals why not the bracts? if the bracts why not the leaves? The theory would thus do away with the possibility of indigestion in plants, or at least the primordial plant, could not have been troubled in this way, for it would have had no digestive organs.

I have only to add that the flowers in question offered no explanation of the great peculiarity presented by the existence of a single row of stamens in number double that of the petals. Possibly this may be the result of bifurcation at a very early stage of development. It was hardly to be expected that they would throw any light on the equally curious "obdiplostemonous" arrangement'in the nearly-allied genus Platytheca, in which there "are two rows" of stamens, the outermost being superposed or opposite to the petals, instead of being alternate with them, as is usually the case in stamens so placed. A possible explanation of this in a sense partly consistent with Mr. Allen's views would be to consider the petal as in this case an outgrowth from the stamen, and not a separate organ, a view that has been propounded in the case of Primulaceæ and some Malvaceæ. MaXWELl T. Masters

\section{Fruit of Opuntia}

DR. ERNST's abnormal fruit of Opuntia, as figured at p. 77 , appears to be similar to one described and illustrated by $\mathrm{Zucca}$ rini (Abhandl. d. math. phys. Class., B. iv., Abth. 1., tab. ii.) in the case of Cereus serpentinus, but as Dr. Ernst gives no details as to the arrangement of the vascular bundles, it is impossible to say that the two cases are exactly parallel. The resemblance to certain gourds. (Cucurbits), wherein the upper part of the fruit protrudes beyond the dilated end of the flowerstalk, may also be pointed out. MAXWell T. MASTERS

\section{Hawk Moth Larva}

I FORWARD a sketch of the larva of a hawk moth found in the Khasi Hills, Assam, in the position it assumes when disturbed. Its resemblance to a snake will be at once evident.

The head (just visible in the sketch) and two first segments of the body are retracted, and the third pair of

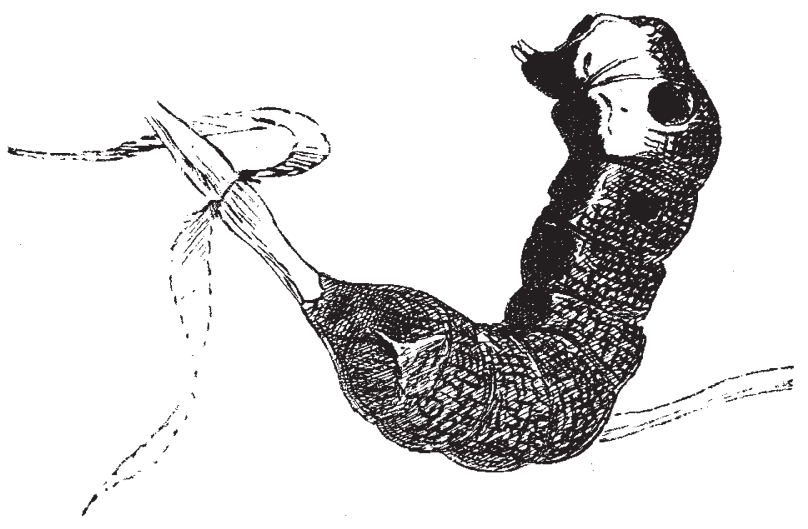

pale horn colour have a rough resemblance to lower jaw or teeth. Small imperfect ocelli in the third segment might be taken for nostrils. The ocellus on the 5 th segment, which however, is

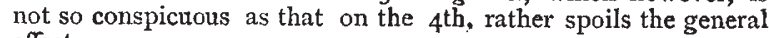
effect.

The colour is olive brown reticulated with black and imitates a reptile's scales very perfectly. The lower parts are black, 